\title{
Integrative Analysis of Gene Expression and miRNAs Reveal Biological Pathways Associated with Bud Paradormancy and Endodormancy in Grapevine
}

\author{
Shuchi Smita ${ }^{1,+}{ }^{,}$Michael Robben ${ }^{1}$, Anup Deuja ${ }^{1}$, Monica Accerbi ${ }^{2}$, Pamela J. Green ${ }^{2}$, Senthil Subramanian ${ }^{1}$ (D) \\ and Anne Fennell ${ }^{1, *(D)}$ \\ 1 Edgar McFadden BioStress Laboratory, Agronomy, Horticulture, and Plant Science Department, BioSNTR, \\ South Dakota State University, Brookings, SD 57007, USA; shuchi2803@gmail.com (S.S.); \\ michael.robben@sdstate.edu (M.R.); adeuja25@gmail.com (A.D.); senthil.subramanian@sdstate.edu (S.S.) \\ 2 Department of Plant and Soil Sciences and Delaware Biotechnology Institute, University of Delaware, \\ Newark, DE 19713, USA; accerbi@dbi.udel.edu (M.A.); green@dbi.udel.edu (P.J.G.) \\ * Correspondence: anne.fennell@sdstate.edu; Tel.: +1-605-688-6373 \\ + Current address: Department of Immunology, School of Medicine, University of Pittsburgh, \\ Pittsburgh, PA 15261, USA.
}

check for updates

Citation: Smita, S.; Robben, M.; Deuja, A.; Accerbi, M.; Green, P.J.; Subramanian, S.; Fennell, A. Integrative Analysis of Gene Expression and miRNAs Reveal Biological Pathways Associated with Bud Paradormancy and Endodormancy in Grapevine. Plants 2021, 10, 669. https://doi.org/ $10.3390 /$ plants10040669

Academic Editor: Vesselin Baev

Received: 4 March 2021

Accepted: 24 March 2021

Published: 31 March 2021

Publisher's Note: MDPI stays neutral with regard to jurisdictional claims in published maps and institutional affiliations.

Copyright: (c) 2021 by the authors. Licensee MDPI, Basel, Switzerland. This article is an open access article distributed under the terms and conditions of the Creative Commons Attribution (CC BY) license (https:/ / creativecommons.org/licenses/by/ $4.0 /)$.

\begin{abstract}
Transition of grapevine buds from paradormancy to endodormancy is coordinated by changes in gene expression, phytohormones, transcription factors, and other molecular regulators, but the mechanisms involved in transcriptional and post-transcriptional regulation of dormancy stages are not well delineated. To identify potential regulatory targets, an integrative analysis of differential gene expression profiles and their inverse relationships with miRNA abundance was performed in paradormant (long day (LD) 15 h) or endodormant (short day (SD), $13 \mathrm{~h}$ ) Vitis riparia buds. There were 400 up- and 936 downregulated differentially expressed genes in SD relative to LD buds. Gene set and gene ontology enrichment analysis indicated that hormone signaling and cell cycling genes were downregulated in SD relative to LD buds. miRNA abundance and inverse expression analyses of miRNA target genes indicated increased abundance of miRNAs that negatively regulate genes involved with cell cycle and meristem development in endodormant buds and miRNAs targeting starch metabolism related genes in paradormant buds. Analysis of interactions between abundant miRNAs and transcription factors identified a network with coinciding regulation of cell cycle and epigenetic regulation related genes in SD buds. This network provides evidence for cross regulation occurring between miRNA and transcription factors both upstream and downstream of MYB3R1.
\end{abstract}

Keywords: grapevine; miRNA; photoperiod; dormancy; regulatory network

\section{Introduction}

Grapevine is a seasonally indeterminate temperate fruit crop that grows in different climates across the world. The grape industry is currently threatened by global climate change that brings with it increasingly variable temperatures in spring, fall and winter. Transition of buds from paradormancy to endodormancy synchronizes the seasonal growth cycle of the grapevine and prepares it for winter [1]. Paradormancy limits bud break in response to signals from within the vine but external to the bud maintaining its growth potential but inhibiting bud break during the growing season. Upon perception of a genotype-appropriate environmental signals, the paradormant axillary bud transitions into endodormancy, where-in bud break is controlled by factors internal to the bud [2]. Unlike many fruit tree crops, which set terminal buds to enter dormant conditions in preparation for overwintering, grapevines abscise their shoot tips and develop endodormancy in the compound axillary buds that have developed continuously throughout the growing season [3-5]. 
Physiological and transcriptomic studies in grapevine and other species reveal multiple molecular changes occur during bud endodormancy induction [3-10]. An increase in sucrose and starch metabolism and secondary metabolism related gene expression is observed during the natural temporal transition from paradormancy to endodormancy [4,7]. A comparison of microarray data from multiple species (Euphorbia esula, Solanum tubersum, Rubus ideaus, Vitis vinifera, Arabidopsis, Populus hybrid, V. riparia) show an increase in cell cycle control and circadian rhythm gene expression as common factors across the species during endodormancy induction [5,11]. In leafy spurge (Euphorbia esula L.) crown buds, endodormancy induction relies upon ethylene signaling and crosstalk between photoperiod and temperature response pathways [12]. During the transition from paradormancy to endodormancy in $V$. vinifera buds, an increase expression of ABA related transcripts and a decrease in the expression of gibberellin and auxin signaling pathways is observed [9]. Similarly, during photoperiod-induced endodormancy in $V$. riparia an increase in abscisic acid, raffinose, trehalose, and resveratrol concentrations occurs [5].

A classic model of endodormancy induction in apical buds of perennial plants involves photoperiod dependent reduction of phytochrome $\mathrm{A}$, constans, and flowering locus T/centrorodialis-like1 (FT1/CENL1) gene expression $[13,14]$. This model does not explain; however, the role of transcriptional regulators and environmental factors that affect induction of endodormancy, such as, the MADS-box transcription factors or temperature dependent growth cessation $[15,16]$. Recent work in cherry trees, suggests that epigenetic regulation could play a vital role in dormancy transitions resulting in largescale transcriptomic modification and an increase in expression of chromatin remodeling proteins [13,14,17].

Even though microRNAs (miRNAs) play a significant role in post-transcriptionally regulating plant developmental processes, responses to the environment, and biotic and abiotic stress during seed dormancy, few studies have looked at its role in regulating bud dormancy induction [18-22]. Some reports suggest that cold and drought stress induced miRNAs play an important role in grapevine cold tolerance $[23,24]$. A few miRNAs show a more direct role in dormancy-associated processes. Crosstalk between miR6390 and C-repeat binding factor (CBF), dormancy-associated MADS-box (DAM) and flowering locus T (FT2) genes play important roles in regulating endodormancy in pear and cherry flower buds and other trees $[10,17,20,22]$. Similarly, both miRNA156 and miRNA172 were found to regulate seed dormancy and flowering time in lettuce (Lactuca sativa) and Arabidopsis thaliana in a delay of germination 1 (DOG1) dependent manner [21]. However, no photoperiod-inducible miRNAs with a role in regulating the dormancy induction in Vitis species have been reported to this date.

$V$. riparia Michx. 'Manitoba $37^{\prime}$. presents an excellent woody plant model to study the regulation of endodormancy induction as, in contrast to many of the tree because unlike many of the tree species models, it undergoes the dormancy transition in existing compound axillary buds rather than confounding terminal bud organogenesis and dormancy induction at the end of a growing season [7,14,25]. Previous grapevine studies in greenhouse $\left(25\right.$ to $\left.28^{\circ} \mathrm{C}\right)$ indicate that 21 days of short photoperiod treatment $(\mathrm{SD} ; 13 \mathrm{~h})$ results in a delay of bud break with full endodormancy being induced after 28 days in SD photoperiod while the long photoperiod (LD; $15 \mathrm{~h}$ ) treated grapevines remain paradormant [26]. Co-incident with bud endodormancy induction a greater number of downregulated genes were observed during the endodormancy phase starting at 28 days of SD [5]. Therefore, in the present study, RNA-seq was used to analyze differential gene expression at this pivotal stage and miRNA abundance and inverse gene expression analysis and predicted motif gene set enrichment of downregulated genes were used to identify potential regulatory networks associated with bud endodormancy. 


\section{Results}

\subsection{Endodormancy Is Associated with Greater Down-Regulation of Gene Expression Relative} to Paradormancy

Hierarchal clustering indicated the transcriptome profiles of the paradormant (LD) and endodormant (SD) buds are distinctly different (Figure S1, Table S1). There were 1336 genes differentially expressed (DEG) in the buds, of these, 400 were upregulated and 936 were downregulated in the SD buds relative to the LD buds (Table S1). A clear distinction between the two treatments is observed (Figure S1), but there was variability between replications within each photoperiod treatment. Therefore, the DEG identified in this study were compared to the DEG in a previously published microarray study with similar conditions, resulting a strong correlation $\left(\mathrm{R}^{2} 0.8\right.$, Figure S2, Table S1). An overview of changes in biological processes and molecular function was obtained using gene set enrichment analysis (GSEA) with Vitis Network annotation. GSEA results using all expressed genes showed 26 VitisNet pathways were positively enriched in SD, notably glycolysis, phenylpropanoid biosynthesis, and starch and sucrose biosynthesis (Table S2). There were no transcription factor pathways enriched in the SD buds; however, there were 19 transcription factor pathways enriched in LD buds. In addition, hormone signaling pathways were positively enriched in LD relative to SD buds. Gene ontology (GO) analysis of the differentially expressed genes was conducted to identify specific gene function and metabolic pathway enrichments in SD and LD treatments. GO enrichment analysis of the up-regulated genes in SD relative to LD buds identified 10 biological process, two cellular component, and 24 molecular function categories (Figure 1, Table S3). In contrast, there were 136 biological processes, 19 cellular component, and 10 molecular function categories enriched for the down-regulated genes in SD relative to the LD buds. In agreement with the GSEA overview, the enriched GO for biological processes of upregulated genes in SD buds were in oxidation-reduction, phenylpropanoid, lignin, starch catabolic and stress related categories. Molecular function categories for upregulated genes in SD were enriched in oxido-reductase activity and catalytic activity. In contrast, biological processes enriched for the genes downregulated in SD were signaling, cell cycle, chromatin organization, and shoot and floral development related categories.

\section{2. miRNA Abundance Differs in Paradormant (LD) and Endocormant (SD) Buds}

A BLASTN search of SD and LD sequenced small RNAs against the miRBASE repository revealed that 62,612 of the unique small RNA sequences matched with 2626 conserved (validated sequences in any species) and known miRNAs (validated sequences specific to $V$. vinifera) belonging to 1987 miRNAs families, from at least 61 plant species (out of 73 Viridiplantae species in miRBASE) (Figure S3a, Table S4). A set of 2094 unique sequences (corresponding to 339 conserved miRNAs; 224 miR families; in 48 plant species) were classified as highly abundant ( $\geq 20$ counts in both libraries combined) (Table S5). There were 252 conserved miRNAs with $\geq 2$-fold difference in abundance between LD and SD buds, 139 (belonging to $92 \mathrm{miR}$ families) and 113 (belonging to $87 \mathrm{miR}$ families) had a greater abundance in LD and SD, respectively (Table 1). Some miRNAs in the LD (miRNA166m, miRNA3636) and SD (miRNA397b, miR408b, miR156s) had greater than 20-fold change in abundance between the two treatments (Figure S3b, Table S4). The differential abundance of 13 LD and 13 SD abundant miRNAs was validated by qPCR and coinciding with the small RNA sequence abundance, nine of the LD and three of the SD were significantly abundant (Table S5). A regression of the mean log fold change (FC) qPCR values with small RNA-seq $\log$ FC data yielded an $\mathrm{R}^{2}$ value of 0.6 with some of the LD miRNAs showing greater FC. A total of 50 conserved and 11 known miR families were exclusively downregulated during endodormancy induction while 47 conserved and 9 known miR families were exclusively upregulated. Seventeen of these families were significantly differentially expressed with a Wilcoxon $p$-value $<0.05$ and all but one had a fold change greater than two (Table 1). 


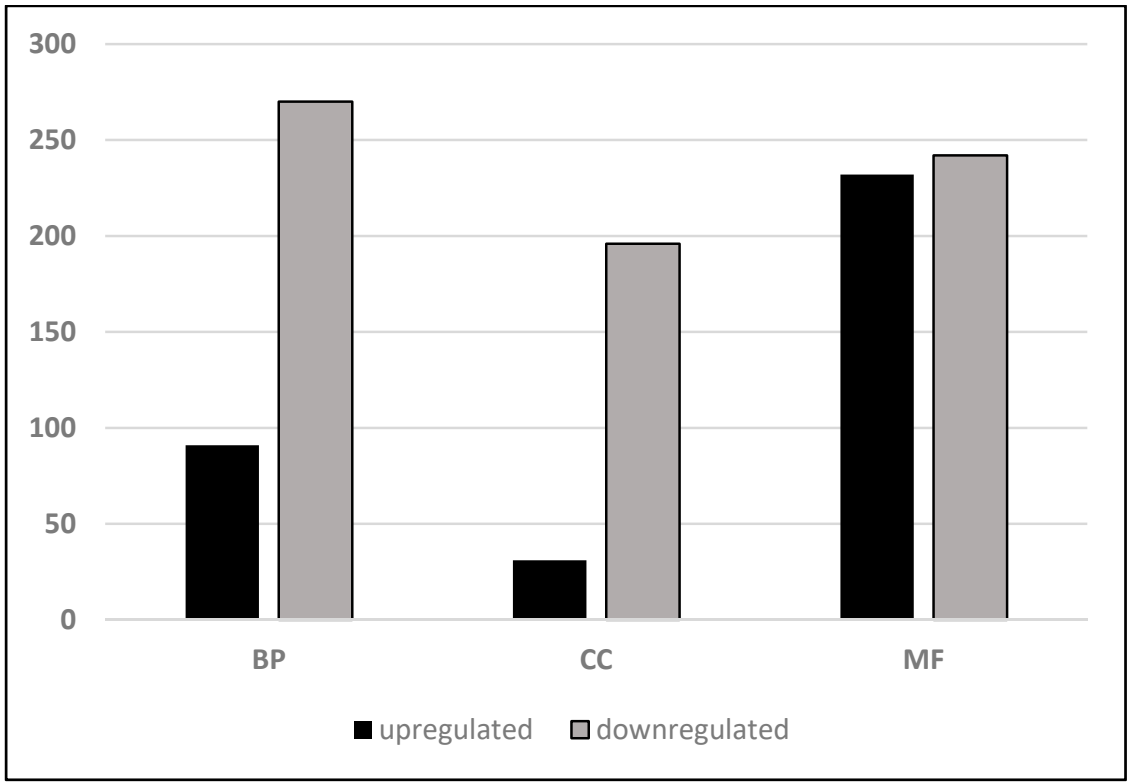

(a)

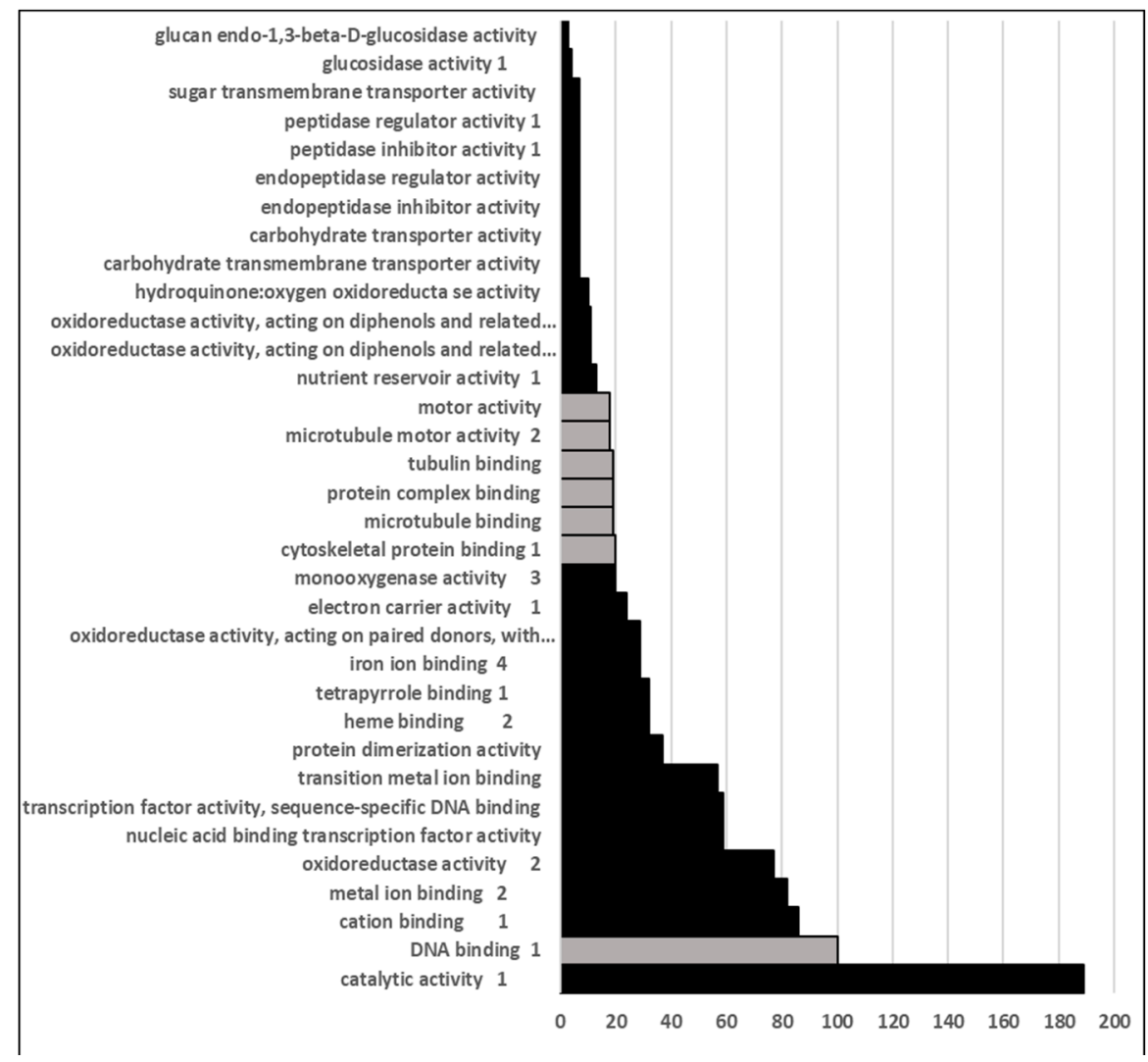

(b)

Figure 1. (a). Biological processes (BP), cellular component (CC), and molecular function (MF) gene ontology categorization of differentially expressed genes in $V$. riparia buds. Bars represent the gene ontology of non-redundant differentially expressed genes upregulated (black) and downregulated (gray) in SD relative to LD buds. (b) Molecular function categories enriched in upregulated (black) and down (gray) differentially expressed genes. 
Table 1. Significant enrichment of miRNA families during paradormancy (LD, $15 \mathrm{~h}$ ) and endodormancy induction (SD, $13 \mathrm{~h}$ ) in V. riparia buds.

\begin{tabular}{|c|c|c|c|c|c|c|}
\hline miR Family & $\begin{array}{c}\text { Fold } \\
\text { (LD vs. SD) }\end{array}$ & $\begin{array}{c}\text { FDR } \\
\text { Adjusted } \\
p \text {-Value }\end{array}$ & $\begin{array}{l}\text { Mean LD } \\
\text { Count }\end{array}$ & $\begin{array}{l}\text { Mean SD } \\
\text { Count }\end{array}$ & $\begin{array}{c}\text { miRNA } \\
\text { Sequences } \\
\text { with } \geq 20\end{array}$ & $\operatorname{miR}$ Family $\operatorname{Logo} 1$ \\
\hline 166 & 2.7 & $9.2 \times 10^{-10}$ & 604 & 225 & 431 & CUUCGAUUCC:C \\
\hline 167 & 2.5 & $6.1 \times 10^{-13}$ & 2933 & 1164 & 170 & UGAAGCUGCCAGCA \\
\hline 894 & 4.1 & $4.3 \times 10^{-5}$ & 237 & 58 & 64 & \\
\hline 3636 & 4.7 & $4.1 \times 10^{-7}$ & 929 & 197 & 45 & CUG \\
\hline 3623 & 3.1 & $7.0 \times 10^{-4}$ & 629 & 201 & 42 & ACAAS \\
\hline 169 & 3.2 & $2.6 \times 10^{-2}$ & 264 & 82 & 27 & \\
\hline 390 & 3.0 & $3.4 \times 10^{-2}$ & 936 & 309 & 20 & AAGCUCA \\
\hline 3640 & 3.6 & $1.4 \times 10^{-2}$ & 207 & 58 & 19 & $A G_{S}$ \\
\hline 3637 & 3.0 & $6.6 \times 10^{-3}$ & 145 & 48 & 16 & \\
\hline 164 & 2.5 & $1.1 \times 10^{-2}$ & 25 & 10 & 14 & \\
\hline 391 & 3.0 & $2.7 \times 10^{-2}$ & 563 & 185 & 12 & U \\
\hline 2916 & -2.3 & $3.5 \times 10^{-6}$ & 53 & 121 & 96 & IGAL \\
\hline 3639 & -2.0 & $2.7 \times 10^{-2}$ & 225 & 445 & 45 & UAAA \\
\hline 156 & -3.6 & $1.8 \times 10^{-2}$ & 348 & 1254 & 24 & $\mathrm{AC}$ \\
\hline 397 & -3.4 & $1.3 \times 10^{-2}$ & 347 & 1168 & 16 & Aus: \\
\hline 408 & -3.8 & $3.6 \times 10^{-2}$ & 76 & 289 & 15 & 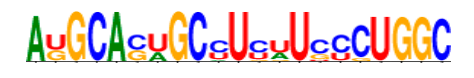 \\
\hline 398 & -3.9 & $1.2 \times 10^{-2}$ & 141 & 545 & 10 & $\mathrm{CCl} \mathrm{C}_{\mathrm{G}}$ \\
\hline
\end{tabular}

1. Denotes the miR family HMM logo for the sequences having $\geq 20$ counts in library. miR families in bold are reported with known vvi miRNA member. (For all miRNAs see Table S4).

\section{3. miRNAs Target Different Genes in Paradormant (LD) and Endodormant (SD) Buds}

Gene target prediction of the LD and SD abundant miRNAs was conducted to elucidate pathways that the miRNAs might regulate during dormancy. A total of $113 \mathrm{LD}$ abundant miRNAs had 1571 potential predicted target genes and 88 SD abundant miRNAs had 1290 potential predicted target genes (Table S6). Many members of the miR166 family, which were abundant in LD buds were predicted to target thaumatin genes, a nonconserved target gene for this miRNA family. Squamosa promoter binding protein-like 4 (SPL4) was predicted to be targeted by miRNA156 (a, b, I, l, s isoforms) abundant in SD buds. GO enrichment analysis of predicted target genes revealed that the biological processes such as post-transcriptional regulation of gene expression and silencing by RNA related genes were enriched in both LD and SD (Figure S3a,b, Table S7). Predicted gene 
targets of LD abundant miRNAs were uniquely enriched in defense response, response to stress, and stimulus related biological processes. In contrast, predicted target genes of the SD abundant miRNAs were uniquely enriched for biological processes related to lignin metabolism and catabolism, aromatic compound catabolism, reproductive system and structure development, and embryo development ending in dormancy (Figure 2, Table S7).

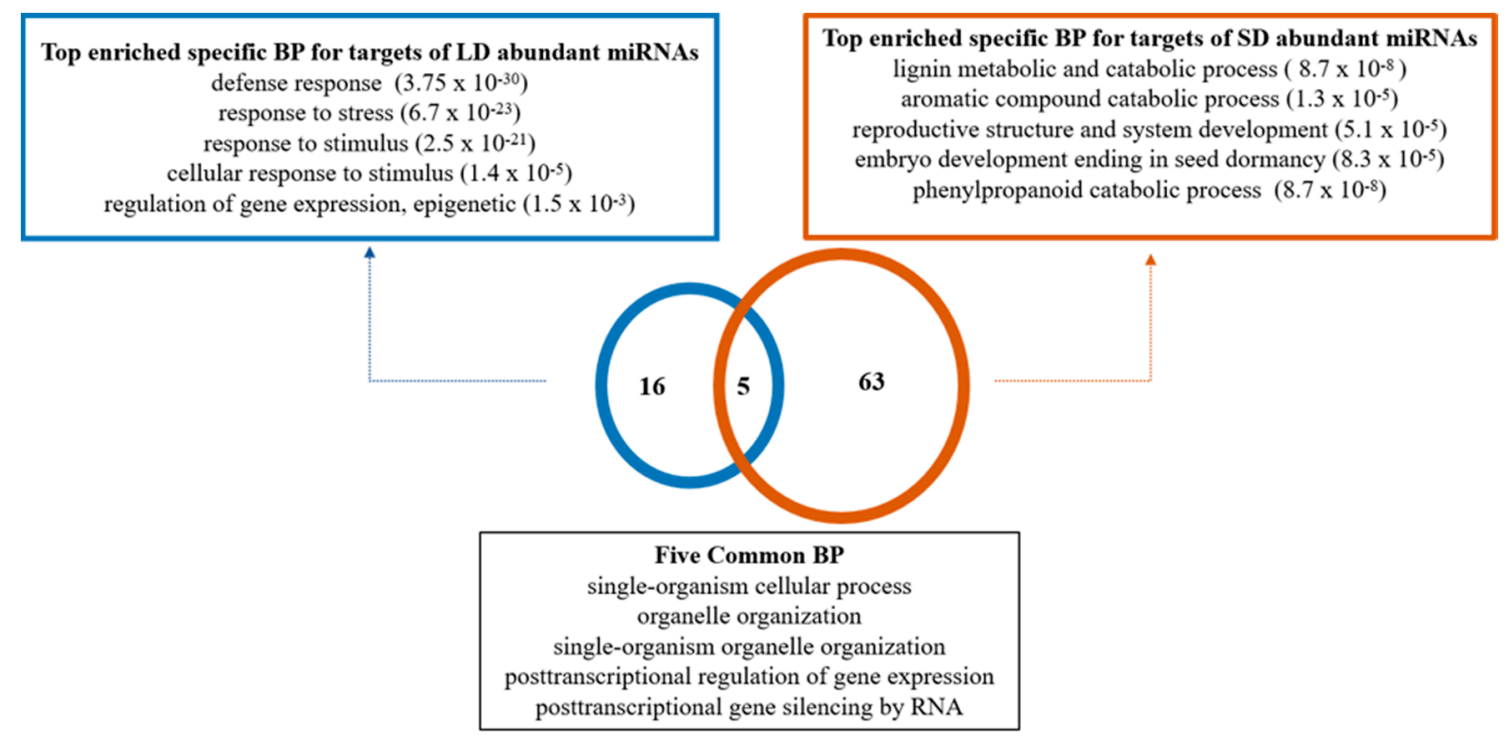

Figure 2. Biological processes (BP) enrichment of predicted targets for abundant miRNAs in V. riparia buds. Blue outlines indicate paradormancy $(\mathrm{LD}, 15 \mathrm{~h})$ and orange outlines indicate endodormancy $(\mathrm{SD}, 13 \mathrm{~h})$ related enriched BP for targets. Significance of BP enrichment was calculated using hypergeometric distribution adjusted by set count sizes (SCS) for multiple hypothesis correction. Adjusted $p$-value is indicated in parenthesis after each biological process GO term.

\subsection{Inverse Expression Association of Predicted Target Genes and Abundant miRNAs}

Using inverse expression analysis of the miRNAs and their predicted target genes that were differentially expressed, 12 predicted target genes of 14 LD abundant miRNAs and 31 predicted target genes of 26 SD abundant miRNAs were identified as inversely correlated in LD and SD buds, respectively (Figure 3a,b; Table S8). LD abundant miRNAs (miR166a, +miR772, miR1863, and miR159) were predicted to target thaumatin, trehalosephosphatase, and isoamylase genes which showed decreased expression levels in LD buds (Table S8). Most of the LD abundant miRNAs predicted target genes were a part of the starch metabolism or pathogen resistance pathways (Figure 3a, Tables S1 and S8).

An inverse expression relationship was found between expression of a squamosal promoter-binding-like protein 4 (SPL4) gene and miR156 in SD buds, with one of the miR156 also predicted to target a basic helix-loop-helix transcription factor (BHLH) (Figure 3b, Tables $\mathrm{S} 1$ and S8). Two ethylene response genes, whose expression was significantly downregulated in SD relative to LD were the predicted targets of the SD abundant miR3633. Interestingly, BHLH, peroxidase, glycoprotein 11, and ferulated 5-hydroxylase genes all had a similar decreased expression pattern in SD buds relative to LD buds from previously published microarray data from our lab. These observations suggest potential post-transcriptional regulation of these genes by the respective miRNAs during dormancy transition. 

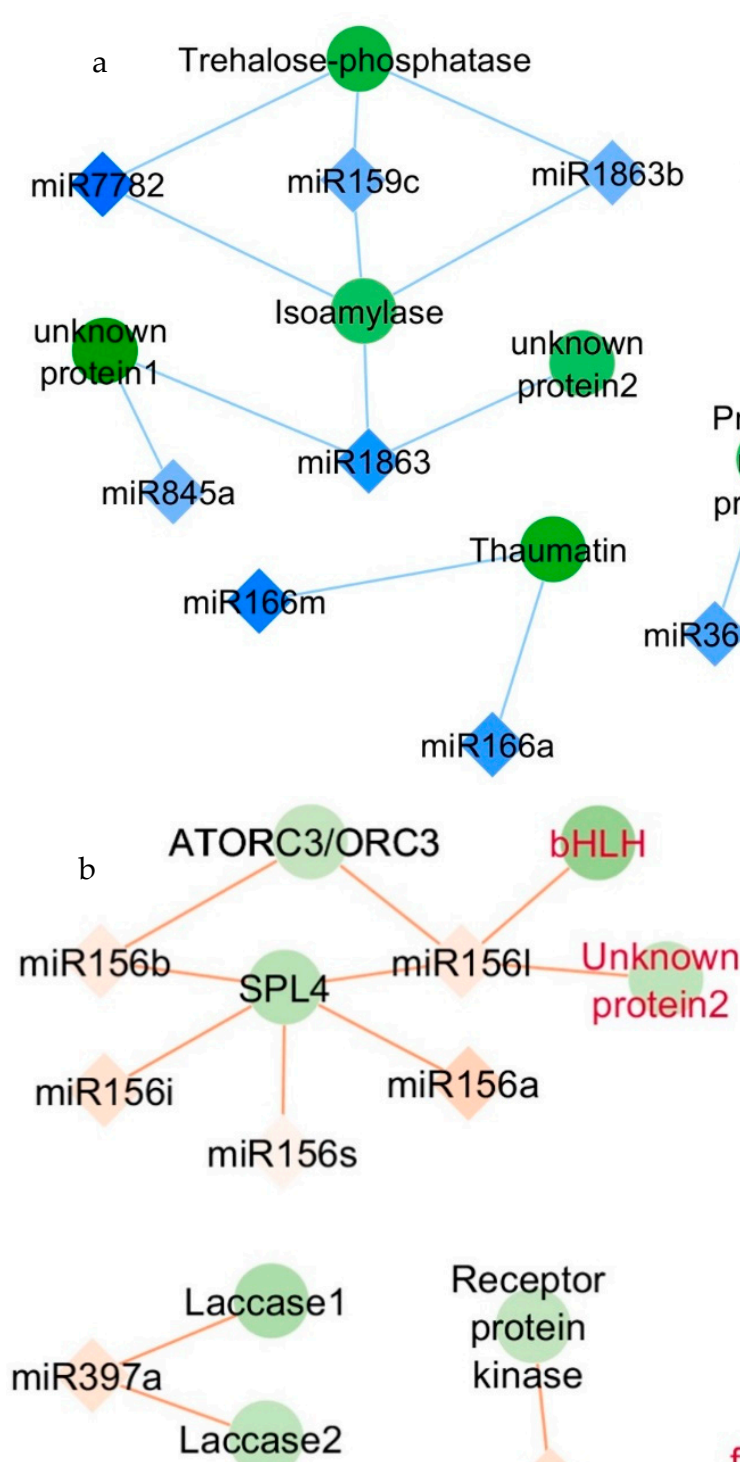
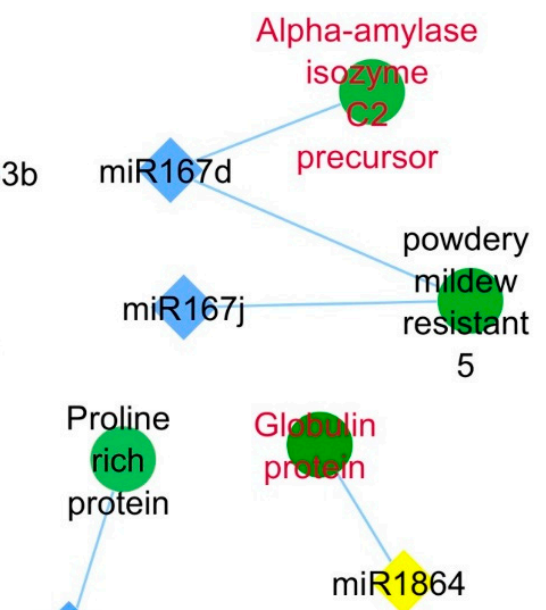

$\operatorname{miR} 3624$

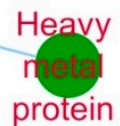

Unusual

floral organs (UFO) Peroxidase

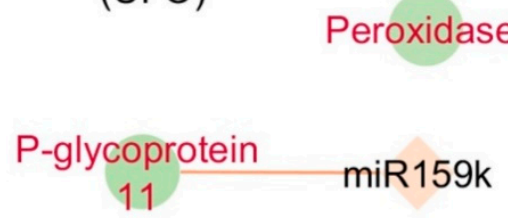
$\begin{array}{ll}\text { Unknown } & \text { miR4394 } \\ \text { protein3 }\end{array}$ miR396a

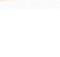
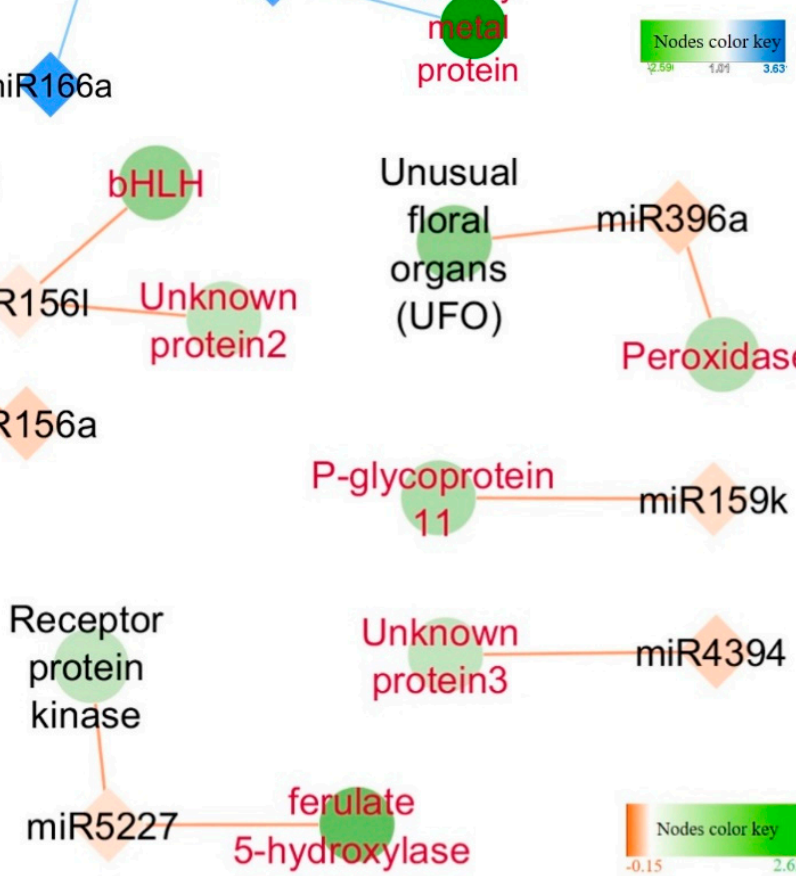

Nodes color key

Figure 3. Example portions of miRNA-mediated (a) Stress networks for paradormant buds (LD, $15 \mathrm{~h}$ ). (b) Meristem regulatory networks for endodormant buds (SD, $13 \mathrm{~h}$ ). in $V$. riparia buds. Nodes are displayed for LD (a, blue diamonds) and SD (b, orange diamonds) abundant miRNAs, their target genes (green circle). The intensity of the node color is directly proportional to their expression. The complete networks of the inverse pattern of target genes are identified in Table S8. Genes identified in red font are genes that were noted to be downregulated in multiple dormancy studies (Table S8).

\subsection{Predition of Transcription Factor Regulatory Network in LD and SD Abundant miRNAs}

Using predicted motif enrichment of transcription factor binding sites, we performed a GSEA of differentially expressed genes using predicted transcription factors as gene sets and found MYB3R1 transcription factor to be the only transcription factor gene set significantly enriched for downregulated genes in the SD. In the SD buds, downregulated genes with MYB3R1 binding motifs in their promoters were involved in pathways belonging to cell cycle, cytoskeleton, extracellular, and vesicular transport, and various other transcription factors. To understand how miRNA and transcriptional regulators might work together in the endodormant bud a network was constructed with transcriptional targets and protein interactors of MYB3R1, as well as miRNAs and their interactions with their predicted targets (Figure 4, Table S9). We observed key genes involved in pathways such 
as the cell cycle and epigenetic modification pathways that were upregulated (ie protein interactors maintenance of methylation (MOM1) and retinoblastoma related 1 (RBR1_1)), or downregulated (cyclins (CYC) and mitotic spindle checkpoint protein (MAD2)), in endodormant buds (Figure 4, Table S9). This network suggests cross regulation between miRNA and transcription factors both upstream and downstream of MYB3R1 (Table S9). In particular, the transcription factors auxin regulation factor 9 (ARF2) and serine/threonine protein kinase aurora (AURORA1) were predicted targets of miR397 and miR156, respectively. Six miRNA families (miR156, 167, 397, 1863, 5139, 8155, 8556) abundant in SD buds were predicted to target members of MYB3R1 network including chromomethylase (CMT), minichromosome maintenance proteins (MCM2,3,4,6), chinese for ugly (TSO1), kinesin, kinesin motor protein (KMOTOR) and AURORA-1 (AURORA1). These miRNAs all target transcription factors or protein interactors that are members of a larger MYB3R1 cell cycle regulatory hub.

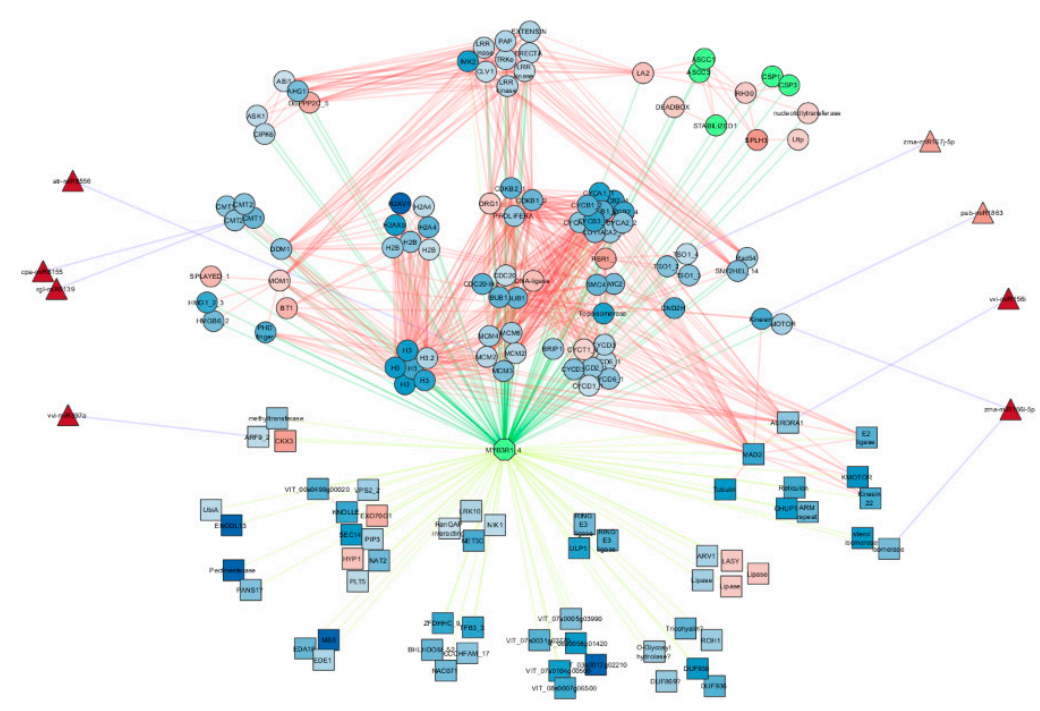

Figure 4. Protein network of MYB3R1 interaction with transcriptional targets (squares), protein interactors (circles), and miRNA (triangles). Transcriptional target, protein interactors, and miRNA nodes are represented by squares, circles, and triangles, respectively. MYB3R1-target interactions are denoted by yellow edges, MYB3R1-protein interactions by green edges, protein-protein interactions by red edges, and miRNA-target by blue edges. The node fill color (blue (negative) to red (positive)) indicates the log fold change expression values for differentially expressed genes and nodes with green fill color were not differentially expressed in SD relative to LD buds (Table S9).

\section{Discussion}

Transcription factors and miRNAs have emerged as major drivers of transcriptional and post-transcriptional regulation during plant development and growth. The largescale sequencing of transcriptomes has been a key instrument in identifying the effect of this regulation in a variety of non-model plant systems [27]. RNA-seq has also been used to explore gene expression of miRNAs and other regulatory elements [28]. Tissue expression profiles of miRNAs has identified important regulators in $V$. vinifera, including those expressed in the dormant bud [29-32]. While RNA-seq has been applied to bud endodormancy in $V$. vinifera [33], gene expression during the shift to endodormancy in $V$. riparia has only been studied using microarray technology [3,5].

In this study, we integrated mRNA and miRNA RNA-seq data to deduce potential regulators in paradormancy maintenance and endodormancy induction. RNA-seq analysis of LD or SD treated $V$. riparia buds revealed 1336 genes differentially regulated between the two treatments. The majority were downregulated in SD relative to LD buds, suggesting transcriptional regulation may be associated with the shift to endodormancy. Genes upregulated upon entering endodormancy are involved in metabolic pathways, phenyl- 
propanoid synthesis, membrane transport, glycolysis, and sucrose and starch metabolism. These results are notable since starch concentrations were found to be high at the onset of endodormancy in the xylem sap of Japanese Pear [34], and trehalose and raffinose production increase to a peak level after 42 days of SD treatment in $V$. riparia [5]. Genes downregulated in association with endodormancy were hormone signaling, transcription factors, cell cycle, and chromatin organization.

Small RNA sequencing data analysis and mapping with miRBASE demonstrated varied abundance of miRNAs among families. There was a lower abundance of annotated miRNAs in endodormant buds, which could be due to the annotated set of our small RNA library containing regulatory elements and also non-regulatory small RNAs and the remains of mRNA degradation. This is supported by the fact that miRNAs upregulated in endodormant conditions have more predicted targets as well as more cases of inverse gene expression with the mRNA data. miR families 166 and 167 were the most significantly upregulated families in paradormant grapevine buds, which is consistent with studies in pear winter flower buds [22].

Using inverse patterns of mRNA and miRNA expression, regulators of both paradormant and endodormant conditions were identified. Most notably, the miRNAs abundance coincided with reduced starch and sucrose metabolism gene expression in LD buds. There is also an inverse relationship between miR159 abundance and the trehalose-6-phosphatase gene expression level in LD but not SD buds. The predicted downregulation of trehalose6phosphatase having a role in promoting paradormancy maintenance is supported by the contrasting enhanced trehalose-6-phosphatase gene expression during bud endodormancy in $V$. riparia [5]. In addition, trehalose-6-phosphate content is also correlated with bud outgrowth potential in potatoes and peas [31,32,35-37] Similarly, miR3624 which was predicted to target heavy metal domain associated protein genes, that have been shown to produce reactive oxygen species, was abundant in paradormant buds in contrast to endodormant buds. In the grapevine rootstock M4, drought stress inhibited miR3624 expression and the heavy metal associated gene is upregulated [24]. Similarly, heavy metal domain associated protein genes were upregulated in endodormant buds in contrast to paradormant buds in this study. Thus, the increased abundance of miRNA3624 in paradormant buds may play a role in limiting active oxygen species production and maintaining paradormancy.

Genes that were predicted to be regulated by miRNAs in SD were related to cell cycle and cell division pathways. This is in agreement with previous findings that endodormancy is associated with the cessation of vegetative, and flower meristem development, while sustained paradormancy is associated with the development of multiple branched floral primordia [38]. The miR156 family of miRNAs, which has been shown to control the meristem cell fate transition in many plants, was prominent in these results [22]. An increased abundance of miR156 was inversely correlated with decreased gene expression of two floral related genes (squamosa-promoter binding protein-like transcription factor gene (SPL4) and unusual floral organ (UFO)) in endodormant buds. In lettuce, reduced miR156 promoted early flowering and seed germination; in contrast, increased miR156 increased seed dormancy [21]. Downregulation of SPL4 by miR156 in switchgrass (Panicum virgatum) SPL4 promoted axillary bud initiation [39] In grapevine, reduced expression of SPL family genes was correlated with endodormancy [4,5]. These imply that miR156 has a strong role in regulating bud dormancy. Another, miRNA482, which we predicted to target and reduce expression of kinesins, has been found to directly impact soybean nodulation, a highly active cell division stage of development [40]. In addition, ethylene-signaling genes were targeted by multiple miRNAs which are highly abundant in the endodormant buds. In conjunction with the findings that most ethylene pathway genes were downregulated we speculate that miRNA negative regulation of the ethylene signaling pathway plays an important role in photoperiod induced endodormancy. In endodormant buds an inverse relation was identified between miR397 abundance and laccase gene expression. Similarly, a marked decrease in laccase and other cellulose synthase genes found during Thompson 
Seedless ( $V$. vinifera) bud dormancy [41]. The regulation of laccase, which has a role in lignin biosynthesis, is well documented in plants; however, whether it has a role in dormancy regulation is not known [42,43].

Transcription factor regulation is an important component of transition into endodormancy in many species and it is widely accepted that DAM transcription factors play a vital role in the process in pear and apricot buds $[13,18,20]$. There were increased miRNA abundances and an inverse expression of several transcription factor predicted targets, including BHLH, SPL4, and ERF105 upon entering endodormancy in $V$. riparia buds (Table S8). MYB3R1 motifs were recently found enriched in differentially expressed genes during hypoxia-related bud break in $V$. vinifera [44]. Similarly, MYB3R1 was the only transcription factor to have motifs significantly enriched in the promoters of downregulated genes in $V$. riparia endodormant buds. While MYB3R1 is not differentially expressed in our data set, upstream protein interactors including LRR-repeat receptor kinases, cell-cycle control genes, and kinesin motor proteins were predominantly downregulated excluding checkpoint proteins such as the plant homolog retinoblastoma related 1 (RBR1) and an ABA insensitive 1 related protein phosphatase $2 \mathrm{C}$ (DBPP2C). Likewise, it is noted in pea that transition of buds from dormant to active growth show results in high levels of phosphorylated RBR1 [45]. Expression of some cell cycle genes such as AURORA1, MAD2, and kinesin appear simultaneously suppressed by MYB3R1 and miRNAs 156, 167, and 1863. This leads us to believe that a signal transduction and miRNA dependent pathway might regulate the activity of MYB3R1 to suppress cell division in preparation for endodormancy. It is noted in Arabidopsis, that MYB3R1, 3, and 5 gene expression is required to suppress cell cycle genes after DNA damage [46]. This network also pointed to the interaction of MYB3R1 with histones and various epigenetic proteins which has not been previously shown in other studies. In particular, the increased expression of MOM1 and decreased expression of decreased DNA methylation 1 (DDM1) genes which could possibly further regulate MYB3R1-dependent gene expression by methylation of DNA or histone H3.

This study like previous grapevine dormancy studies had a greater number of genes downregulated than upregulated upon transitioning to bud endodormancy in grapevine, supporting a potential role for miRNA in transcriptional regulation. Inverse analysis and predicted motif gene set enrichment of downregulated genes identified potential miRNA and transcriptional regulatory networks associated with bud endodormancy. A potential role in paradormancy maintenance was identified for miR159 regulation of trehalose-6phosphatase and miR3624 regulation of heavy metal domain associated protein genes. In endodormancy, a regulatory role is suggested for miR156 and miR396 through downregulation of floral and meristem development related genes. The predicted motif gene set enrichment in downregulated genes identified potential regulatory networks associated with the MYB3R1 transcription factor. This network identified potential cross regulation between miRNA (notably 156, 167 and 1863) and transcription factors up- and downstream of MYB3R1 and involved cell cycle and epigenetic pathways in endodormant buds.

\section{Materials and Methods}

\subsection{Plant Materials and Photoperiod Treatments}

Six-year-old spur pruned ecodormant $V$. riparia 'Manitoba $37^{\prime}$ Michx. (PI588259)) vines were repotted and grown in long photoperiod (LD, $15 \mathrm{~h}$ ) at $25 / 20 \pm 3{ }^{\circ} \mathrm{C}$ day/night temperatures with 600-1400 mol m $\mathrm{m}^{-2} \mathrm{~s}^{-1}$ photosynthetic photon flux in a climate-controlled unshaded glass greenhouse (EnTech Control Systems Inc., Montrose, MN, USA) in Brookings, South Dakota (44.3 N). Grapevines were grown for 30 days post bud break reaching shoot lengths of 10-15 nodes. Three replicate ten-vine experimental units were randomly assigned to each photoperiod treatment of continued LD (paradormancy) or short photoperiod (SD, 13 h; endodormancy) as previously described [5]. After 28 days, three replicate bud samples for each photoperiod were harvested into separate tubes of liquid nitrogen and stored at $-80^{\circ} \mathrm{C}$ until small RNA or total RNA extraction. 


\subsection{RNA Sequencing and Differential Gene Expression Analysis}

Total RNA was extracted from three biological replicates of LD and SD buds using a modified method of Chang et al. [47] as described in Mathiason et al. [3]. DNA free RNA quality and quantity were verified with an Agilent (Santa Clara, CA, USA) 2100 Bioanalyzer RNA 6000 nano chip. RNA-seq libraries for LD and SD bud transcriptomes were prepared and sequenced by Illumina HiScanSQ (100 bp, single strand) at the Cornell University Institute of Biotechnology Genome Facility (Ithaca, NY, USA). The full raw sequencing data were submitted to the GEO database with the accession number GSE95429. Raw read quality and adapter sequences were checked using Fastqc (v. 0.11.3) (http:/ / www.bioinformatics.babraham.ac.uk/projects/fastqc/, accessed on 10 October 2020). Further adapter trimming and filtering of poor quality sequences were performed using Cutadapt (v. 1.8.1) and Prinseq-lite (v0.20.4) (minimum phred quality score $=20$, minimum post trimming length $=20$ ), respectively [48]. The reference genome based alignment and assembly of clean reads were performed using Tuxedo pipeline [49]. The V. vinifera PN40024 12X V2 genome was indexed using Bowtie2 (v.2.2.4). Quality reads were aligned using TopHat (v2.0.13) to the indexed reference genome and guided using gene models available for V. vinifera (http:/ / genomes.cribi.unipd.it/DATA/ GFF/F17, accessed on 4 October2019). Mapped reads in each library were assembled into transcripts using cufflinks (v. 2.2.1). Assembled transcript mapping to the reference genome, identified a total of 29,288 genes expressed at a threshold of FPKM $\geq 1$ in at least one of the dormancy phases. Principal component analysis indicated that the treatment replicates separated into LD and SD groups. Differential gene expression (LD vs. SD) was analyzed using cuffdiff (v. 2.2.1) with adjusted $p$-value $\leq 0.05$ and fold change ( $\geq$ or $\leq 1)$. $V$. vinifera PN40024 12X_V1 and _V3 gene annotation and VitisNet annotation were used to identify the significant genes [50]. Differentially expressed genes from a microarray study with similar photoperiod treatments [5] was utilized to calculate correlation with current RNseq data using "cor.test" function in R.

\subsection{Transcriptome Functional Enrichment Analyses}

Functional enrichment analysis was performed by the g:Profiler (http:/ /biit.cs.ut.ee/ gprofiler/ accessed on 10 October 2020) using the hypergeometric distribution adjusted by set count sizes (SCS) for multiple hypothesis correction [51]. SCS threshold removes enriched false positive GO terms and prioritizes truly significant results. Each gene was assigned a GO term, if it crossed the threshold adjusted $p$-value (SCS) $\leq 0.05$. GO annotation of Vitis genes was obtained from the V. vinifera 12X_V1 genome annotation as background.

\subsection{VitisNet Gene Set Enrichment Analysis (GSEA)}

Gene Set Enrichment Analysis (GSEA) was conducted using read count data from each of the three replicates for each treatment using GSEA-P 2.0 (http:/ / www.broad.mit.edu/ GSEA accessed on 10 October 2020) [52] and 247 VitisNet pathways (https:/ / openprairie. sdstate.edu/vitisnet-12x_files/ accessed on 10 October 2020) including at least 7 genes. The recommended GSEA-P 2.0 default parameters of 1000 permutations, nominal $p$-value $<0.05$ and FDR q-value $<0.25$ were used to identify enriched molecular pathways related to LD or SD. Positive significantly enriched pathways are generally upregulated in SD bud relative to LD bud.

\subsection{Small RNA Library Construction, Sequencing and Processing}

Total RNA was isolated using Plant RNA Reagent (Invitrogen/Thermo Fisher Scientific, Carlsbad, CA, USA), and low molecular weight RNA was purified from total RNA by PEG8000/ $\mathrm{NaCl}$ precipitation [53,54]. Two small RNA libraries were constructed: (1) a pool of LD and (2) a pool of SD buds as described [55] with the following: RNA oligos for RNA ligation:5' RNA adapter: 5'-GUUCAGAGUUCUACAGUCCGACGAUC-3' $3^{\prime}$ RNA adapter: 5'-pUCGUAUGCCGUCUUCUGCUUG-idT-3' (p, phosphate; idT, inverted deoxythymidine); DNA oligo for reverse transcription: RT-primer (5'-CAAGCAGAA GACGGCATACGA-3'); DNA oligos for PCR amplification:5' PCR primer (5'-AATGATACG 
GCGACCACCGACAGGTTCAGAGTTCTACAGTCCGA-3'), 3' PCR primer (5'-CAAGCAG AAGACGGCATACGA- $3^{\prime}$ ). The Illumina sequencing of small RNA libraries from LD and SD led to the generation of 7,761,608 and 6,530,774 non redundant sequences, respectively. Filtering the low quality reads and adaptor contaminations resulted in 7,591,740 (LD) (total read count $24,452,821$ ) and 6,352,594 (SD) (total read count 22,206,946) unique sequences that were retained for further analysis.

High quality, non-redundant small RNA sequences were aligned with the miRNA precursor/mature miRNAs of all Viridiplantae (green plants) in miRBase 21.0 (http:/ / www. mirbase.org/ accessed on 4 October 2019) to identify annotated (conserved and known in $V$. vinifera (vvi) miRNAs in $V$. riparia. Utilizing Blastn, sequences with $\leq 2$ mismatches were considered as potential miRNAs. Sequences matched with already deposited $V$. vinifera miRNAs were designated as "known in vvi" and sequences that matched to other plant species were designated as "conserved miRNAs". The total conserved and miRNAs sequences known in vvi with $\geq 20$ counts total in the LD and SD libraries were called "highly abundant" miRNAs and were used for further analyses. Reads per million (RPM) value was calculated for each identified miRNAs sequence (normalized expression $=$ number of reads for a sequence/number of total reads for all sequences in that library $\times 1,000,000$ ). The differential abundance of miRNAs sequences between LD and SD was calculated as fold-change $=\log _{2}($ miRNAs normalized RPM in 'LD' /normalized RPM in 'SD'). miR families abundant ( $\geq 2$ fold), only in LD or SD library were called "specifically abundant" miR families. Using a Wilcoxon Ranked Sum test, total read counts of miRNAs that annotated to specific miRNA families were used to calculate a $p$-value statistic between LD and SD expression in each family.

Quantitative PCR validation was conducted for 26 miRNAs, 13 each from LD and SD abundant miRNAs from 18 miRNA families. cDNA was produced for each of three biological replicates using $500 \mathrm{ng}$ of RNA as described by Turner et al. [56]. cDNA and genespecific primers (Table S5) were combined with 2X SYBR Master Mix and ROX baseline dye (Thermofisher Scientific, Waltham, MA, USA) and qPCR was performed for three technical replicates of each the three biological replicates of cDNA using the running conditions $95^{\circ} \mathrm{C}$ for $5 \mathrm{~min}$, followed by 45 cycles of $95^{\circ} \mathrm{C}$ for $5 \mathrm{~s}, 60^{\circ} \mathrm{C}$ for $10 \mathrm{~s}$ and $72{ }^{\circ} \mathrm{C}$ for $1 \mathrm{~s} . \Delta \mathrm{Ct}$ of each miRNA was calculated against the $\mathrm{U} 6$ control in each pooled cDNA group using the equation $\left(\Delta \mathrm{Ct}=\mathrm{Ct}_{\mathrm{Control}}-\mathrm{Ct}_{\mathrm{Gene}}\right)$ and the $\Delta \Delta \mathrm{Ct}$ was calculated using the equation $\left(\Delta \Delta \mathrm{Ct}=\Delta \mathrm{Ct}_{\mathrm{LD}}-\Delta \mathrm{Ct}_{\mathrm{SD}}\right)$. Log fold change values were determined and statistical analyses for pairwise comparison of the $\Delta \mathrm{Ct}$ values were by Student's $t$-test, $p$-value $<0.05$ for the LD and SD treatments.

\subsection{Target Prediction for Abundant miRNAs}

Empirical parameters were used with an in-house perl script to run Patscan (http: / /blog.theseed.org/servers/2010/07/scan-for-matches.html accessed on 4 October 2019) and RNAduplex [57] for recognition of potential targets of abundant miRNAs using $V$. vinifera as reference mRNAs. The empirically inferred parameters tuned with maximum one mismatch at position 2-9, no mismatch at position 10-11 and 4 mismatch from position 12 to end $[58,59]$. The output was parsed to identify hits on complementary strand with $<3$ consecutive mismatches and relative minimum free energy (MFE) $\geq 70 \%$ compared to perfectly complementary target genes. Cytoscape software was used to visualize the miRNA-target regulatory networks [60].

\subsection{Transcription Factor Motif GSEA and Network}

$V$. vinifera specific transcription factor, regulated gene sets from enriched motif predictions in TFDB (downloaded 12/10/2018) were used in a GSEA analysis through the gage package [61]. Predictions of protein interactions in V. vinifera were obtained from BIOgrid and limited to interactions with a confidence score greater than 700. Protein interactions combined with Protein-DNA interactions and miRNA-target predictions were constructed into a network using Cytoscape [60] complimented with RNA-seq log fold change scores. 
Supplementary Materials: The following are available online at https://www.mdpi.com/article/10 $.3390 /$ plants10040669/s1, Figure S1: Hierarchical clustering showing distinct transcriptome profile of LD and SD bud samples. Figure S2: Correlation between microarray and rnaseq differentially expressed genes in buds with 28 days of LD and SD treatment. $\mathrm{R}^{2}=0.80, p$-value $<2.2 \times 10^{-16}$. Figure S3: (a) Length distribution of miRNAs sequences in LD and SD buds. Numbers in legend indicate total number of miRNA sequences in LD or SD library. (b) Frequency of differential abundance of miRNAs in paradormant and endodormant buds. Paradormancy (LD, $15 \mathrm{~h}$ ) in blue bars and endodormancy induction $(\mathrm{SD}, 13 \mathrm{~h}$ ) in orange bars. Table S1: V. riparia differentially expressed up- and downregulated genes in short day (SD, $13 \mathrm{~h}$ ) relative to long day (LD, $15 \mathrm{~h}$ ) buds. $n=3$, adjusted $p$-value $\leq 0.05$ and fold change $(\geq 1$ or $\leq-1)$. Table S2: Gene set enrichment analysis (GSEA) of all genes expressed in SD and LD buds. A positive normalized enrichment score (NES) indicates VitisNet pathways enriched in SD and a negative NES indicates pathways enriched in LD treatments at nominal $p$-value $<0.05$ and false discovery rate (FDR) q-value $<0.25$. Table S3: GO enrichment analysis for differentially expressed genes $V$. riparia short day (SD, $13 \mathrm{~h}$ ) and long day (LD, $15 \mathrm{~h}$ ) buds. Significance of enrichment was calculated using hypergeometric distribution adjusted by set count sizes (SCS) for multiple hypothesis correction ( $p$-value, $\mathrm{SCS} \leq 0.05)$. Table S4: List of all $V$. riparia bud miRNAs abundant under short day (SD, $13 \mathrm{~h}$ ) and long day (LD, $15 \mathrm{~h})$ photoperiod treatment. Table S5: qPCR primer sequences for validation and log fold change of qPCR and miRNA abundance for long day (LD, $15 \mathrm{~h}$ ) and short day (SD, $13 \mathrm{~h})$ V. riparia buds. In primer column, the lowercase letters indicate the gene specific sequence and the uppercase letters indicate the universal sequence. Table S6: List of predicted target genes of abundant miRNAs under short day (SD, $13 \mathrm{~h}$ ) and long day (LD, $15 \mathrm{~h}$ ) photoperiod treatment in V. riparia bud. Table S7: GO enrichment analysis of target genes for V. riparia long day (SD, $13 \mathrm{~h}$ ) and long day (LD, $15 \mathrm{~h}$ ) abundant bud miRNAs. Significance of BP enrichment was calculated using hypergeometric distribution adjusted by set count sizes (SCS) for multiple hypothesis correction ( $p$-value, SCS $\leq 0.05$ ). Table S8: Inverse expression pattern of predicted target genes for long day (LD, $15 \mathrm{~h}$ ) and short day (SD, $13 \mathrm{~h})$ miRNAs as identified with our RNA-seq and compared with other dormancy data sets (marked in red fonts in Figure 4). Table S9: Protein network of MYB3R1 interaction with transcriptional targets, protein interactors, and miRNA. Values are expressed as Log FC of SD relative to LD buds.

Author Contributions: Conceptualization, A.F. and P.J.G.; methodology, S.S. (Shuchi Smita), M.R., M.A., P.J.G., A.D., A.F. and S.S. (Senthil Subramanian); validation, M.R.; formal analysis, S.S. (Shuchi Smita), M.R., A.F. and A.D.; resources, A.F., P.J.G. and S.S. (Senthil Subramanian); data curation, S.S. (Shuchi Smita), A.F. and A.D.; writing-original draft preparation, S.S. (Shuchi Smita) and M.R.; writing-review and editing, A.F., S.S. (Senthil Subramanian); visualization, S.S. (Shuchi Smita), M.R. and A.F.; supervision, A.F.; project administration, A.F.; funding acquisition, A.F. All authors have read and agreed to the published version of the manuscript.

Funding: This work was supported by the National Science Foundation/EPSCOR Cooperative Agreement \# [IIA1355423], the State of South Dakota through BioSNTR, a South Dakota Research Innovation Center and South Dakota Agriculture Experiment Station.

Institutional Review Board Statement: Not applicable.

Informed Consent Statement: Not applicable.

Data Availability Statement: The RNA-seq data has been deposited in NCBI under accession number GSE95707.; The small RNA data has been deposited at http:/ / openprairie.sdstate.edu/vitis_ riparia_microRNA_data, accessed on 4 March 2021.

Acknowledgments: We acknowledge South Dakota State University's high-performance computing clusters for data analysis, technical support from South Dakota State University's Research Information Technology team.

Conflicts of Interest: The authors declare no conflict of interest. The funders had no role in the design of the study; in the collection, analyses, or interpretation of data; in the writing of the manuscript, or in the decision to publish the results. 


\section{References}

1. Fennell, A. Freezing Tolerance and Injury in Grapevines. J. Crop. Improv. 2004, 10, 201-235. [CrossRef]

2. Lang, G.A.; Early, J.D.; Martin, G.C.; Darnell, R.L. Endo-, para-, and ecodormancy: Physiological terminology and classification for dormancy research. HortScience 1987, 22, 371-377.

3. Mathiason, K.; He, D.; Grimplet, J.; Venkateswari, J.; Galbraith, D.W.; Or, E.; Fennell, A. Transcript profiling in Vitis riparia during chilling requirement fulfillment reveals coordination of gene expression patterns with optimized bud break. Funct. Integr. Genom. 2009, 9, 81-96. [CrossRef] [PubMed]

4. Díaz-Riquelme, J.; Grimplet, J.; Martínez-Zapater, J.M.; Carmona, M. Transcriptome variation along bud development in grapevine (Vitis vinifera L.). BMC Plant Biol. 2012, 12, 181. [CrossRef]

5. Fennell, A.Y.; Schlauch, K.A.; Gouthu, S.; Deluc, L.G.; Khadka, V.; Sreekantan, L.; Grimplet, J.; Cramer, G.R.; Mathiason, K.L. Short day transcriptomic programming during induction of dormancy in grapevine. Front. Plant Sci. 2015, 6, 834. [CrossRef]

6. Ning, D.-L.; Liu, C.-C.; Liu, J.-W.; Shen, Z.; Chen, S.; Liu, F.; Wang, B.-C.; Yang, C.-P. Label-free quantitative proteomics analysis of dormant terminal buds of poplar. Mol. Biol. Rep. 2013, 40, 4529-4542. [CrossRef]

7. Ruttink, T.; Arend, M.; Morreel, K.; Strome, V.; Rombauts, S.; Fromm, J.; Bhalerao, R.P.; Boerjan, W.; Rohde, A. A Molecular Timetable for Apical Bud Formation and Dormancy Induction in Poplar. Plant Cell 2007, 19, 2370-2390. [CrossRef]

8. Zhang, Y.X.; Yu, D.; Tian, X.L.; Liu, C.Y.; Gai, S.P.; Zheng, G.S. Differential expression proteins associated with bud dormancy release during chilling treatment of tree peony (Paeonia suffruticosa). Plant Biol. 2015, 17, 114-122. [CrossRef]

9. Kahlil-Ur-Rehman, M.; Sun, L.; Li, C.-X.; Faheem, M.; Wang, W.; Tao, J.-M. Comparative RNA-seq based transcriptomic analysis of bud dormancy in grape. BMC Plant Biol. 2017, 17, 18. [CrossRef]

10. Maurya, J.P.; Bhalerao, R.P. Photoperiod- and temperature-mediated control of growth cessation and dormancy in trees: A molecular perspective. Ann. Bot. 2017, 120, 351-360. [CrossRef]

11. Horvath, D.P.; Chao, W.S.; Suttle, J.C.; Thimmapuram, J.; Anderson, J.V. Transcriptome analysis identifies novel responses and potential regulatory genes involved in seasonal dormancy transitions of leafy spurge (Euphorbia esula L.). BMC Genom. 2008, 9, 536. [CrossRef] [PubMed]

12. Doğramac1, M.; Foley, M.E.; Chao, W.S.; Christoffers, M.J.; Anderson, J.V. Induction of endodormancy in crown buds of leafy spurge (Euphorbia esula L.) implicates a role for ethylene and cross-talk between photoperiod and temperature. Plant Mol. Biol. 2013, 81, 577-593. [CrossRef]

13. Horvath, D. Common mechanisms regulate flowering and dormancy. Plant Sci. 2009, 177, 523-531. [CrossRef]

14. Rohde, A.; Bhalerao, R.P. Plant dormancy in the perennial context. Trends Plant Sci. 2007, 12, 217-223. [CrossRef]

15. Yamane, H.; Kashiwa, Y.; Ooka, T.; Tao, R.; Yonemori, K. Suppression Subtractive Hybridization and Differential Screening Reveals Endodormancy-associated Expression of an SVP/AGL24-type MADS-box Gene in Lateral Vegetative Buds of Japanese Apricot. J. Am. Soc. Hortic. Sci. 2008, 133, 708-716. [CrossRef]

16. Heide, O.M.; Prestrud, A.K. Low temperature, but not photoperiod, controls growth cessation and dormancy induction and release in apple and pear. Tree Physiol. 2005, 25, 109-114. [CrossRef]

17. Rothkegel, K.; Sandoval, P.; Soto, E.; Ulloas, L.; Riveros, A.; Lillo-Carmona, V.; Cáceres-Molina, J.; Almeida, A.M.; Meneses, C. Dormant but active: Chilling accumulation modulates the epigenome and transcriptome of Prunus avium during bud dormancy. Front. Plant Sci. 2020, 11, 1115. [CrossRef]

18. Barakat, A.; Sriram, A.; Park, J.; Zhebentyayeva, T.; Main, D.; Abbott, A. Genome wide identification of chilling responsive microRNAs in Prunus persica. BMC Genom. 2012, 13, 481. [CrossRef] [PubMed]

19. Jeyaraj, A.; Chandran, V.; Gajjeraman, P. Differential expression of microRNAs in dormant bud of tea (Camellia sinensis (L.) O. Kuntze]. Plant Cell Rep. 2014, 33, 1053-1069. [CrossRef]

20. Niu, Q.; Li, J.; Cai, D.; Qin, M.; Jia, H.; Bai, S.; Hussain, S.; Liu, G.; Teng, Y.; Zheng, X. Dormancy-associated MADS-box genes and microRNAs jointly control dormancy transition in pear (Pyrus pyrifolia white pear group) flower bud. J. Exp. Bot. 2016, 67, 239-257. [CrossRef]

21. Huo, H.; Wei, S.; Bradford, K.J. DELAY OF GERMINATION1 (DOG1) regulates both seed dormancy and flowering time through microRNA pathways. Proc. Natl. Acad. Sci. USA 2016, 113, E2199-E2206. [CrossRef] [PubMed]

22. Bai, S.; Saito, T.; Ito, A.; Tuan, P.A.; Xu, Y.; Teng, Y.; Moriguchi, T. Small RNA and PARE sequencing in flower bud reveal the involvement of sRNAs in endodormancy release of Japanese pear (Pyrus pyrifolia 'Kosui'). BMC Genom. 2016, 17. [CrossRef]

23. Sun, X.; Fan, G.; Su, L.; Wang, W.; Liang, Z.; Li, S.; Xin, H. Identification of cold-inducible microRNAs in grapevine. Front. Plant Sci. 2015, 6. [CrossRef]

24. Pagliarani, C.; Vitali, M.; Ferrero, M.; Vitulo, N.; Incarbone, M.; Lovisolo, C.; Valle, G.; Schubert, A. Accumulation of MicroRNAs Differentially Modulated by Drought Is Affected by Grafting in Grapevine. Plant Physiol. 2017, 173, 2180-2195. [CrossRef]

25. Vimont, N.; Fouché, M.; Campoy, J.A.; Tong, M.; Arkoun, M.; Yvin, J.-C.; Wigge, P.A.; Dirlewanger, E.; Cortijo, S.; Wenden, B. From bud formation to flowering: Transcriptomic state defines the cherry developmental phases of sweet cherry bud dormancy. BMC Genom. 2019, 20, 974. [CrossRef] [PubMed]

26. Wake, C.M.F.; Fennell, A. Morphological, physiological and dormancy responses of three Vitis genotypes to short photoperiod. Physiol. Plant 2000, 109, 203-210. [CrossRef]

27. Garg, R.; Jain, M. RNA-seq for transcriptome analysis in non-model plants. In Legume Genomics, Methods and Protocols; Rose, R.J., Ed.; Humana Press: Totowa, NJ, USA, 2013; pp. 43-58. 
28. Lu, J.; Getz, G.; Miska, E.A.; Alvarez-Saavedra, E.; Lamb, J.; Peck, D.; Sweet-Crdero, A.; Ebert, B.L.; Mak, R.H.; Ferrando, A.A.; et al. MicroRNA expression profiles classify human cancers. Nature 2005, 435, 834-838. [CrossRef] [PubMed]

29. Wang, C.; Shangguan, L.; Kibet, K.N.; Wang, X.; Han, J.; Song, C.; Fang, J. Characterization of microRNAs Identified in a Table Grapevine Cultivar with Validation of Computationally Predicted Grapevine miRNAs by miR-RACE. PLoS ONE 2011, 6, e21259. [CrossRef]

30. Wang, C.; Wang, X.; Kibet, K.N.; Song, C.; Zhang, C.; Li, X.; Han, J.; Fang, J. Deep sequencing of grapevine flower and berry short RNA library for discovery of novel microRNAs and validation of precise sequences of grapevine microRNAs deposited in miRBase. Physiol. Plant 2011, 143, 64-81. [CrossRef] [PubMed]

31. Wang, C.; Leng, X.; Zhang, Y.; Kayes, E.; Zhang, Y.; Sun, X.; Fang, J. Transcriptome-wide analysis of dynamic variations in regulation modes of grapevine microRNAs on their target genes during grapevine development. Plant Mol. Biol. 2014, 84, 269-285. [CrossRef]

32. Kullan, J.B.; Pinto, D.L.P.; Bertolini, E.; Fasoli, M.; Zenoni, S.; Tornielli, G.B.; Pezzotti, M.; Meyers, B.C.; Farina, L.; Pe, M.E.; et al. miRVine, a microRNA expression atlas of grapevine based on small RNA sequencing. BMC Genom. 2015, 16, 393.

33. Khalil-Ur-Rehman, M.; Wang, W.; Xu, Y.-S.; Haider, M.S.; Li, C.-X.; Tao, J.-M. Comparative Study on Reagents Involved in Grape Bud Break and Their Effects on Different Metabolites and Related Gene Expression during Winter. Front. Plant Sci. 2017, 8, 1340. [CrossRef]

34. Sakamoto, D.; Moriguchi, T.; Sugiura, T.; Ito, A. Effects of dormancy progression and low-temperature response on changes in the sorbitol concentration in xylem sap of Japanese pear during winter season. Tree Physiol. 2013, 33, 398-408.

35. Debast, S.; Nunes-Nesi, A.; Hajirezaei, M.R.; Hofmann, J.; Sonnewald, U.; Fernie, A.R.; Bornke, F. Altering trehalose-6-phosphate content in transgenic potato tubers affects tuber growth and alters responsiveness to hormones during sprouting. Plant Physiol. 2011, 156, 1754-1771. [CrossRef]

36. Sonnewald, S.; Sonnewald, U. Regulation of potato tuber sprouting. Planta 2014, 239, 27-38. [CrossRef] [PubMed]

37. Fichtner, F.; Barbier, F.F.; Feil, R.; Watanabe, M.; Annunziata, M.G.; Chabikwa, T.G.; Höfgen, R.; Stitt, M.; Beveridge, C.A.; Lunn, J.E. Trehalose 6-phosphate is involved in triggering axillary bud outgrowth in garden pea (Pisum sativum L.). Plant J. 2017, 92, 611-623. [CrossRef] [PubMed]

38. Sreekantan, L.; Mathiason, K.; Grimplet, J.; Schlauch, K.; Dickerson, J.A.; Fennell, A.Y. Differential floral development and gene expression in grapevines during long and short photoperiods suggests a role for floral genes in dormancy transitioning. Plant Mol. Biol. 2010, 73, 191-205. [CrossRef] [PubMed]

39. Gou, J.; Fu, C.; Liu, S.; Tang, C.; Debnath, S.; Flanagan, A.; Ge, Y.; Tang, Y.; Qingzhen, J.; Larson, P.R.; et al. The miR156-SPL4 module predominantly regulates aerial axillary bud formation and controls shoot architecture. New Phytol. 2017, 216, 829-840. [CrossRef]

40. Li, H.; Deng, Y.; Wu, T.; Subramanian, S.; Yu, O. Mis-expression of miR482, miR1512, and miR1515 Increases Soybean Nodulation. Plant Physiol. 2010, 153, 1759-1770. [CrossRef]

41. Rubio, S.; Dantas, D.; Bressan-Smith, R.; Pérez, F.J. Relationship between Endodormancy and Cold Hardiness in Grapevine Buds. J. Plant Growth Regul. 2016, 35, 266-275. [CrossRef]

42. Lu, S.; Li, Q.; Wei, H.; Chang, M.-J.; Tunlaya-Anukit, S.; Kim, H.; Liu, T.; Song, T.; Sun, Y.-H.; Yuan, L.; et al. Ptr-miR397a is a negative regulator of laccase genes affecting lignin content in Populus trichocarpa. Proc. Natl. Acad. Sci. USA 2013, 110, 10848-10853. [CrossRef]

43. Swetha, C.; Basu, D.; Pachamuthu, K.; Tirumalai, V.; Nair, A.; Prasad, M.; Shivaprasad, V. Major Domestication-Related phenotypes in Indica Rice are due to loss of miRNA-mediated laccase silencing. Plant Cell 2018, 30, 2649-2662. [CrossRef]

44. Meitha, K.; Agudelo-Romero, P.; Signorelli, S.; Gibbs, D.J.; Considine, J.A.; Foyer, C.H.; Considine, M.J. Developmental control of hypoxia during bud burst in grapevine. Plant Cell Environ. 2018, 41, 1154-1170. [CrossRef] [PubMed]

45. Shimizu-Sato, S.; Ike, Y.; Mori, H. PsBR1 encodes a pea retinoblastoma-related protein that is phosphorylated in axillary buds during dormancy-to-growth transition. Plant Mol. Biol. 2008, 66, 125-133. [CrossRef] [PubMed]

46. Bourbosse, C.; Vegesna, N.; Law, J.A. SOG1 activator and MYB3R repressors regulate a complex DNA damage network in Arabidopsis. Proc. Natl. Acad. Sci. USA 2018, E12453-E122462. [CrossRef]

47. Chang, S.; Puryear, J.; Cairney, J. A simple and efficient method for isolating RNA from pine trees. Plant Mol. Biol. Rep. 1993, 11, 113-116. [CrossRef]

48. Schmieder, R.; Edwards, R. Quality control and preprocessing of metagenomic datasets. Bioinformatics 2011, $27,862-864$. [CrossRef] [PubMed]

49. Trapnell, C.; Roberts, A.; Goff, L.; Pertea, G.; Kim, D.; Kelley, D.R.; Pimentel, H.; Sazberg, S.L.; Rin, J.L.; Pachter, L. Differential gene and transcript expression analysis of RNA-seq experiments with TopHat and Cufflinks. Nat. Protoc. 2012, 7, 562-578. [CrossRef]

50. Grimplet, J.; Cramer, G.R.; Dickerson, J.A.; Mathiason, K.; Van Hemert, J.; Fennell, A.Y. VitisNet, 'Omics' Integration through Grapevine Molecular Networks. PLoS ONE 2009, 4, e8365. [CrossRef] [PubMed]

51. Reimand, J.; Kull, M.; Peterson, H.; Hansen, J.; Vilo, J. g: Profiler-A web-based toolset for functional profiling of gene lists from large-scale experiments. Nucleic Acids Res. 2007, 35, W193-W200. [CrossRef] 
52. Subramanian, A.; Tamayo, P.; Mootha, V.K.; Mukherjee, S.; Ebert, B.L.; Gillette, M.A.; Paulovich, A.; Pomeroy, S.L.; Golub, T.T.; Lander, E.S.; et al. Gene set enrichment analysis, A knowledge-based approach for interpreting genome-wide expression profiles. Proc. Natl. Acad. Sci. USA 2005, 102, 15545-15550. [CrossRef]

53. Accerbi, M.; Schmidt, S.A.; De Paoli, E.; Park, S.; Jeong, D.-H.; Green, P.J. Methods for isolation of total RNA to recover miRNAs and other small RNAs from diverse species. Methods Mol. Biol. 2010, 592, 31-50.

54. Meyer, B.C. Plant MicroRNAs_Methods and Protocols; Meyers Blake, C., Ed.; Springer: Berlin/Heidelberg, Germany, 2010; Available online: http:/ / www.springer.com/us/book/9781603270045 (accessed on 8 November 2020).

55. Lu, C.; Meyers, B.C.; Green, P.J. Construction of small RNA cDNA libraries for deep sequencing. Methods 2007, 43, 110-117. [CrossRef]

56. Turner, M.; Adhikari, S.; Subramanian, S. Optimizing stem-loop qPCR assays through multiplexed cDNA synthesis of U6 and miRNAs. Plant Signal. Behav. 2013, 8, e24918. [CrossRef] [PubMed]

57. Lorenz, R.; Bernhart, S.H.; Höner zu Siederdissen, C.; Tafer, H.; Flamm, C.; Stadler, P.F.; Hofaker, I.L. Vienna RNA Package 2.0. Algorithms Mol. Biol. 2011, 6, 26. [CrossRef]

58. Allen, E.; Xie, Z.; Gustafson, A.M.; Carrington, J.C. microRNA-directed phasing during grans-Acting siRNA biogenesis in plants. Cell 2005, 121, 207-221. [CrossRef]

59. Schwab, R.; Palatnik, J.F.; Riester, M.; Schommer, C.; Schmid, M.; Weigel, D. Specific Effects of MicroRNAs on the Plant Transcriptome. Dev. Cell 2005, 8, 517-527. [CrossRef] [PubMed]

60. Shannon, P.; Markiel, A.; Ozier, O.; Baliga, N.S.; Wang, J.T.; Ramage, D.; Amin, N.; Schwikowski, B.; Ideker, T. Cytoscape: A software environment for integrated models of biomolecular interaction networks. Genome Res. 2003, 13, 2498-2504. [CrossRef]

61. Luo, W.; Friedman, M.; Shedden, K.; Hankenson, K.; Woolf, P. GAGE: Generally applicable gene set enrichment for pathway analysis. BMC Bioinform. 2009, 10, 161. [CrossRef] [PubMed] 